\title{
Ventilatory Strategies for Hypoxemia During Cardiac Surgery: Survey Validation for Anesthesiologists in Brazil
}

\author{
Celso Augusto Martins Parra ${ }^{1}$, Maria José Carvalho Carmona, TSA ², José Otávio Costa Auler Junior, TSA ${ }^{3}$, \\ Luiz Marcelo Sá Malbouisson, TSA 4
}

\begin{abstract}
Summary: Parra CAM, Carmona MJC, Auler Junior JOC, Malbouisson LMS - Ventilatory Strategies for Hypoxemia during Cardiac Surgery: Survey Validation for Anesthesiologists in Brazil.

Background and objectives: Perioperative hypoxemia is common in cardiac surgeries, and atelectasis is the main cause. Besides, we can mention extracorporeal circulation (ECC), dissection of internal thoracic arteries, and previous clinical status of the patient among others as its causes. The present study elaborated an anonymous questionnaire to observe ventilatory strategies for hypoxemia in cardiac surgeries adopted by five thousand anesthesiologists all over the country.
\end{abstract}

Methods: Questionnaires were sent via e-mail for five thousand anesthesiologists in Brazil.

Results: Out of the questionnaires sent, 81 valid responses were received. Among the answers, 65 (80\%) anesthesiologists use volume-controlled ventilation (VCV), while 16 (20\%) prefer pressure-controlled ventilation (PCV). The tidal volume (Vt) used is lower than $10 \mathrm{~mL}^{\mathrm{kg}}{ }^{-1}$, for $46(61 \%)$

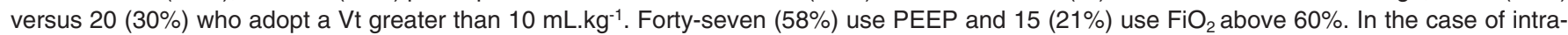
operative hypoxemia, $20.9 \%$ increase or introduce PEEP, $70.3 \%$ increase the $\mathrm{FiO}_{2}, 19.7 \%$ use alveolar recruitment maneuvers, $13.5 \%$ increase the tidal volume, and $20.9 \%$ check for the presence of failures in the anesthesia equipment. Responses were sent from 15 states.

Conclusions: The conducts described in the questionnaires are compatible with those of the international literature. Adjusting the questionnaires format and the way to approach anesthesiologists, new studies could be undertaken.

Keywords: ANESTHESIOLOGY: medical practice; COMPLICATIONS: atelectasis, hypoxemia; SURGERY, Cardiac: extracorporeal circulation.

[Rev Bras Anestesiol 2010;60(4): 406-414] CElsevier Editora Ltda.

\section{INTRODUCTION}

Perioperative hypoxemia is a complication with a high incidence in cardiac surgeries ${ }^{1}$, resulting in increased time of invasive respiratory support ${ }^{2}$ and in the incidence of infections ${ }^{3}$ culminating in longer stay in the intensive care unit, and consequently in total hospital costs. Hedenstierna and Rothen ${ }^{4}$ indicate atelectasis as the main cause of intraoperative hypoxemia, and its causes and strategies will be discussed later. Some particular aspects o cardiac surgeries, such as the presence of extracorporeal circulation (ECC), dissection

\footnotetext{
Received from the CET/SBA of Hospital das Clínicas da Faculdade de Medicina da Universidade de São Paulo (HCFMUSP), São Paulo, SP

1. Third year Resident at the CET/SBA of HCFMUSP

2. Anesthesiology Professor of FMUSP; Director of the Anesthesiology Department of HC of FMUSP

3. Anesthesiology Professor of FMUSP; Director of the Anesthesiology and Surgical Intensive Care Department of InCor of HCFMUSP

4. Physician; Coordinator of the Surgical ICU of the Anesthesiology Department of HCFMUSP; Coordinator of the Surgical Unit of Critical Patients of HSPE; Doctor in Medical Sciences - FMUSP
}

Submitted on March 30, 2010

Approved on April 5, 2010

Correspondence to:

Dr. Celso Augusto Martins Parra, A/C Dr. Luiz Marcelo Sá Malbouisson

Divisão de Anestesia do HC da FMUSP - UTI Cirúrgica

Av. Dr. Enéas de Carvalho Aguiar, 255 - Prédio dos Ambulatórios - 8oandar

05403-900 - São Paulo, SP, Brazil

Phone: 55 (11) 3069-6787

E-mail: malbouisson@hcnet.usp.br of internal thoracic arteries for myocardial revascularization, as well as the baseline condition of the patient undergoing this surgery require increased attention to the management of perioperative hypoxemia ${ }^{5}$. Chart 1 shows the causes of hypoxemia seen in cardiac surgeries.

Since it is a relatively common intercurrence, several strategies for its treatment, preventive and therapeutic, have been described. Chart 2 shows the main conducts.

The objective of the present study was to validate a questionnaire for anesthesiologists specialized in cardiac surgeries on the conducts for intraoperative hypoxemia and its applicability for future researches.

\section{METHODS}

A questionnaire was elaborated (Annex I) and sent by e-mail to 5,000 anesthesiologists in Brazil with an active e-mail at the Brazilian Society of Anesthesiology (SBA, from the Portuguese). Along with the questionnaire a brief explanation about the study, as well as a solicitation for their participation, were sent. Besides, the anonymity of the answers of the participants was assured. They were inquired about their preferred ventilation modality, ventilatory parameters, mixture of gases used, the resources offered by the anesthesia equipment, and their conduct in face of intraoperative hypoxemia. Anesthesiologists who do not work with anesthesia for cardiac surgeries were requested 
Annex I - Questionnaire on the use of mechanical ventilation during cardiac surgery in Brazil

How do you adjust the following parameters of the respirator during cardiac surgery?

1. Ventilation Modality Used

Pressure-controlled（）Volume-controlled（）SIMV（）

2. Tidal Volume: (in $\mathrm{mL} / \mathrm{kg}$ )

3. If you use pressure-controlled ventilation, which is the maximal pressure limit: $\left(\mathrm{cmH}_{2} \mathrm{O}\right)$

4. Respiratory rate: (bpm)

5. Do you commonly use positive end-expiratory pressure (PEEP)?

YES ( ) NO ( )

6. If yes, which level of PEEP do you use? $\left(\mathrm{cmH}_{2} \mathrm{O}\right)$

7. What is the ration Inspiratory time/Expiratory time used? 1

not to answer the questionnaire. In order to validate the national reach, therefore avoiding a bias of a standardized conduct, it was included a question about the county where the interviewee practices anesthesia, but without identifying the respondent. Lastly, a space was left at the end of the questionnaire for final considerations and comments. Only the questionnaires in which all questions were answered and declared experience in the area of anesthesia for cardiac surgery were included in the study. Anesthesiologists not associated with SBA or without an active e-mail registered at the entity were not included in the study. Answers in which the space for considerations and comments was not filled out were not excluded.

\section{RESULTS}

Along a two-week period we received 82 answers, of which 81 were considered complete excluding one of them for incomplete answers.

Regarding the ventilatory modality of choice 65 (80\%) anesthesiologists preferred volume-controlled ventilation (VCV); the remaining $20 \%$ (16 anesthesiologists) preferred pressurecontrolled ventilation (PCV). Synchronized intermittent mandatory ventilation (SIMV) was not chosen by any of the respondents. Dividing the answers according to the parameters of tidal volume in two groups, $46(61 \%)$ use a tidal volume 
lower than $10 \mathrm{~mL} . \mathrm{kg}^{-1}$ while 29 (39\%) use tidal volumes higher than $10 \mathrm{~mL} \cdot \mathrm{kg}^{-1}$. Positive end-expiratory pressure (PEEP) was adopted by 47 (58\%) anesthesiologists while 15 (21\%) used an inspired fraction of oxygen $\left(\mathrm{FiO}_{2}\right)$ above $60 \%$.

Chart 1 - Causes of Hypoxemia in Cardiac Surgery

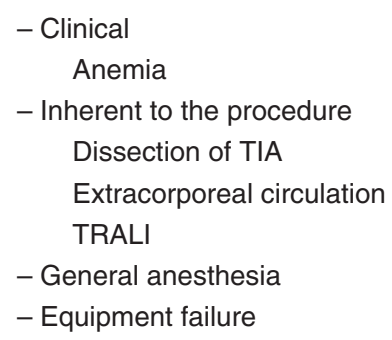

Chart 2 - Risk Factors for Hypoxemia in Cardiac Surgery

Chronic obstructive pulmonary disease

Diabetes mellitus

Prior AMI

Ventricular dysfunction

Need of extracorporeal circulation

Weight

Age

Chart 3 - Conducts when Anesthesiologists in Brazil are Faced with Hypoxemia

Increased $\mathrm{FiO}_{2}$

Increased respiratory rate

Increased tidal volume

Increased PEEP

Manual ventilation

Alveolar recruitment maneuver

Remove $\mathrm{N}_{2} \mathrm{O}$

Hemodynamic evaluation

Review of the pulse oximeter

Review the system of the anesthesia equipment

Chart 4 - Respondents per State

\begin{tabular}{lc}
\hline Amazonas & 2 \\
Bahia & 3 \\
Ceará & 2 \\
Distrito Federal & 5 \\
Espírito Santo & 4 \\
Goiás & 2 \\
Minas Gerais & 8 \\
Paraná & 10 \\
Pernambuco & 1 \\
Rio de Janeiro & 5 \\
Rio Grande do Sul & 6 \\
Santa Catarina & 5 \\
São Paulo - Capital & 13 \\
São Paulo - Interior & 12 \\
Tocantins & 1 \\
\hline
\end{tabular}

Since it was an open question the conduct in face of hypoxemia generated several answers and as a rule more than one per anesthesiologist. Chart 3 shows all responses; the most frequent were: increased or introduction of (PEEP) $(20.9 \%)$, increased $\mathrm{FiO}_{2}$ (70.3\%), increased in tidal volume (13.5\%), alveolar recruitment maneuvers (19.7\%), and checking for leak or failure of the anesthesia equipment (20.9\%).

The geographic distribution included 15 states of all Brazilian regions with predominance of the state of São Paulo $(32 \%)$, and half of those were from the capital of the state. Chart 4 shows the number of answers per state.

\section{DISCUSSION}

The main difficulty of the study was to estimate a satisfactory number of answers to determine the applicability of the questionnaire. Even in organized societies, such as the American (American Society of Anesthesiologists - ASA), or the British (The Royal College of Anaesthetists) it is not possible to obtain an exact number of physicians who exert the activity of anesthesiologist; there is a specific international society for the field (International Society of Cardiovascular Anaesthesia) even though many specialized anesthesiologists are not associated with it. Based on a Canadian master's degree thesis ${ }^{6}$ with a questionnaire on monitoring in cardiac anesthesia it was possible to obtain an approximate number of anesthesiologists specialized in cardiovascular surgery $(n=278)$ since all cardiac surgery services and their respective anesthesiologists were listed. The method used was the safest: according to the data of the local health agency, all services of cardiac surgery were listed, their professionals were contacted and listed, and a personalized questionnaire with an answer-letter was sent to the hospital for each anesthesiologist specialized in cardiac surgery, which was sent again after two weeks, and non-respondents were contacted by telephone. This method generated $76.8 \%$ of responses. At the same time, a census undertaken by the Canadian government ${ }^{7}$ observed that in the same region 1,651 physicians were anesthesiologists. Approximately $17 \%$ of the anesthesiologists from Eastern Canada were specialized in cardiovascular surgery. Those studies were undertaken 10 years ago, a time with a greater number of cardiac surgeries, which is reduced today due to the advancement of less invasive techniques, such as angioplasty. It is believed that nowadays this proportion of specialists is smaller.

In Brazil, it is also difficult to estimate officially the proportion of anesthesiologists since there are non-registered anesthesiologists and/or non-active in the SBA. If we use the number of anesthesiologists furnished by the society for mailing of the questionnaire as a number very close to reality, and extrapolate from the Canadian data the proportion of specialists in cardiovascular surgery, we have approximately 850 anesthesiologists in this specialty in Brazil. Therefore, we estimate that only $9.5 \%$ of the specialists in cardiovascular anesthesia answered the questionnaire. The frequency of respondents was for sure a reflection of the approach method (e-mail) and to opened questions which although they had frequent answers compatible with the data in the literature they also 
generated answers like "depends on the patient" or "I usually do not have hypoxemia in the operating room".

As for the results, a classical study compared two strategies of ventilation in 861 patients with acute lung damage ${ }^{8}$; in one group traditional tidal volume $\left(12 \mathrm{~mL} . \mathrm{kg}^{-1}\right)$ with maximal pressure of $50 \mathrm{cmH}_{2} \mathrm{O}$ was used, while the other group used low tidal volume $\left(6 \mathrm{~mL} . \mathrm{kg}^{-1}\right)$ with a maximal pressure peak of $30 \mathrm{cmH}_{2} \mathrm{O}$. The study was interrupted due to the large difference in mortality between both groups (39.8 vs. $31.0 \%)$. Schultz ${ }^{9}$ reviewed retrospective and observational studies of protective strategies in patients with ARDS that suggest a causal relationship between high tidal volume and lung damage, but they did not observe clear benefits from using low tidal volumes. Despite the lack of evidence we observed in the present study that $61 \%$ of the anesthesiologists try to maintain the tidal volume lower than $10 \mathrm{~mL}$. $\mathrm{kg}^{-1}$ to minimize pulmonary damage.

The main models of study on PEEP also involve acute lung damage whose extreme is represented by the acute respiratory distress syndrome (ARDS), in which excess of pulmonary inflammatory fluid, both interstitial and alveolar, is the mechanism of formation of atelectasis. Positive end-expiratory pressure has benefits in the strategy of pulmonary protection by stabilizing the end-expiratory volume and preventing alveolar collapse. Donahoe enumerated those strategies ${ }^{10}$ and indicated that PEEP was responsible for minimizing atelectrauma and biotrauma The first one corresponds to the mechanical damage imposed to the alveolus that is in the limit of collapse and, at each respiratory cycle it is completely inflated and deflated, and the last is the inflammatory reaction triggered by the mechanical trauma caused by the first. Among the responses, we observed that $58 \%$ use PEEP although this feature was available in $87 \%$ of the anesthesia equipment. Despite the evidence in the literature and availability of this feature, it is believed that this difference was due to the technical difficulty of the surgical team to operate with PEEP.

Excessive oxygen can cause damage of the alveolar tissue by forming superoxide radicals ${ }^{11}$. In a study involving patients with acute pulmonary damage ${ }^{12}$, it was observed that high oxygen concentrations could promote reabsorption atelectasis when compared to patients who received lower concentration of oxygen. Despite this, $21 \%$ of the individuals use high oxygen concentrations (above 60\%).

The increase in PEEP is widely disseminated in reversing atelectasis, with $20.98 \%$ of the answers. The increase in oxygen delivery although controversial is used by $70.6 \%$ of the anesthesiologists. Tidal volume is increased by $13.5 \%$ of the respondents.

Alveolar recruitment maneuver (ARM), also described in some studies as a vital capacity maneuver, consists on the temporary increase in the pressure of the airways, opening atelectatic alveoli with PEEP above the critical alveolar closing pressure. In a review undertaken in 2004, Oczenski et al. ${ }^{13}$ observed evidence of benefits of applying alveolar recruitment maneuvers in patients undergoing ECC and in patients who needs high oxygen concentrations. In the present study, 19\% of those interviewed perform alveolar recruitment maneuvers when faced with hypoxemia in cardiac surgeries.

Leak in the anesthesia equipment can cause both hypoxemia and intraoperative consciousness ${ }^{14}$. Although it is not a cause of hypoxemia widely investigated the sociocultural context inserts a bias on the clinical reasoning generating worries of checking the equipment in $19.7 \%$ of those interviewed.

In a British questionnaire on conducts when facing hypoxemia in pediatric anesthesia ${ }^{15}$, the authors observed that up to $16 \%$ of the anesthesiologists use inspired fraction of $\mathrm{O}_{2}$ higher than $40 \%$, which is close to the number of Brazilian anesthesiologists in which $21 \%$ use an inspired fraction of oxygen greater than $60 \%$. The format of the questionnaire applied after the study in question is similar.

In the section of comments, some experiences were enriching and certainly will provide data to improve the approach to the subject. A frequent complaint (seven respondents) was regarding the degree of complexity of the anesthesia equipment that does not allow them to adopt the conducts mentioned in the study, except for the increase in $\mathrm{FiO}_{2}$. As an example, here is one of those comments: "In my town, the use of microprocessed devices are not widespread..." Those comments suggest a contrast between large centers and departments located in smaller towns.

\section{CONCLUSION}

The questionnaire on conducts taken when facing hypoxemia in cardiac anesthesia is compatible with the data of the international literature, and it is valid for further studies. Some adjustments, such as transforming open questions into categorical questions and a more personalized approach to the professionals therefore increasing the frequency of responses would be beneficial. 


\section{REFERÊNCIAS / REFERENCES}

01. Singh NP, Vargas FS, Cukier A et al. - Arterial blood gases after coronary artery bypass surgery. Chest, 1992;102:1337-1341.

02. Yende $S$, Wunderink $R$ - Causes of prolonged mechanical ventilation after coronary artery bypass surgery. Chest, 2002;122:245-252.

03. Brooks-Brunn JA - Postoperative atelectasis and pneumonia. Heart Lung, 1995;24:94-115.

04. Hedenstierna G, Rothen HU - Atelectasis formation during anesthesia: causes and measures to prevent it. J Clin Monit Comput, 2000;16:329-35.

05. Magnusson L, Zemgulis V, Wicky $S$ et al. - Atelectasis is a major cause of hypoxemia and shunt after cardiopulmonary bypass: an experimental study. Anesthesiology, 1997;87:1153-1163.

06. Jacka MJ - Survey of Monitoring Practice of Anesthesiologists During Cardiovascular Surgery. Tese: Masters of Science, Clinical Epidemiology, 1999. Department of Community Health - University of Toronto. Disponível em: <https://tspace.library.utoronto.ca/ bitstream/1807/14530/1/MQ45908.pdf>.

07. Canadian Institute for Health Information - Supply, distribution and migration of Canadian physicians, 2000.

08 . Anonymous - Ventilation with lower tidal volumes as compared with traditional tidal volumes for acute lung injury and the acute respiratory distress syndrome. The Acute Respiratory Distress Syndrome Network. N Engl J Med, 2000;342:1301-1308.

09. Schultz MJ - Lung-protective mechanical ventilation with lower tidal volumes in patients not suffering from acute lung injury: a review of clinical studies. Med Sci Monit, 2008;14):RA22-26.

10. Donahoe $M-$ Basic ventilator management: lung protective strategies. Surg Clin North Am, 2006;86:1389-1408.

11. Davis WB, Rennard SI, Bitterman PB et al. - Pulmonary oxygen toxicity. Early reversible changes in human alveolar structures induced by hyperoxia. N Engl J Med, 1983;309:878-883.

12. Aboab J, Jonson B, Kouatchet $A$ et al. - Effect of inspired oxygen fraction on alveolar de recruitment in acute respiratory distress syndrome. Intensive Care Med, 2006;32:1979-1986.

13. Oczenski W, Schwarz S, Fitzgerald RD - Vital capacity manoeuvre in general anaesthesia: useful or useless? Eur J Anaesthesiol, 2004;21:253-259.
14. Myers JA, Good ML, Andrews JJ - Comparison of tests for detecting leaks in the low-pressure system of anesthesia gas machines. Anesth Analg, 1997;84:179-184.

15. Short JA, van der Walt JH - Oxygen in neonatal and infant anesthesia: current practice in the UK. Pediatr Anesth, 2008;18:378-387.

Resumen: Parra CAM, Carmona MJC, Auler Junior JOC, Malbouisson LMS. - Estrategias Ventilatorias Frente a la Hipoxemia en Cirugía Cardíaca: Validación de Cuestionario para Anestesiólogos en Brasil.

Justificativa y objetivos: La hipoxemia perioperatoria ocurre frecuentemente en la cirugía cardíaca, y la atelectasia es su principal causa. Además, podemos citar como causas la circulación extracorpórea (CEC), disección de arterias torácicas internas, status clínico previo del paciente, entre otras. El presente estudio elaboró un cuestionario anónimo para observar las estrategias ventilatorias frente a la hipoxemia en cirugía cardíaca adoptadas por cinco mil anestesiólogos en todo el país.

Método: Fueron enviados cuestionarios por e-mail a cinco mil anestesiólogos de Brasil.

Resultados: De los cuestionarios enviados, se recibieron 81 respuestas válidas. Entre las respuestas, 65 (80\%) anestesiólogos usan ventilación controlada a volumen (VCV) frente a $16(20 \%)$ que prefieren la ventilación controlada a presión (PCV). El volumen (Vt) corriente utilizado es inferior a $10 \mathrm{~mL} . \mathrm{kg}-1$ para $46(61 \%)$ contra 29 (39\%) que adoptan un Vt mayor que $10 \mathrm{~mL} . \mathrm{kg}-1$. Cuarenta y siete (58\%) usan PEEP y 17 (21\%) utilizan $\mathrm{FiO} 2$ por encima del $60 \%$. En el caso de hipoxemia intraoperatoria, 20,9\% aumentan o introducen PEEP, un 70,3\% aumentan la $\mathrm{FiO} 2$, un $19,7 \%$ realizan maniobra de reclutamiento alveolar, un $13,5 \%$ aumentan el volumen corriente y un $20,9 \%$ realizan el chequeo de fallas en el aparato de anestesia. Las respuestas fueron enviadas desde 15 estados.

Conclusiones: Las conductas descritas en los cuestionarios respondidos están a tono con la literatura internacional. Nuevos estudios se podrán hacer ajustando el formato del cuestionario y el abordaje a los anestesiólogos. 